\title{
Editorial
}

\section{REHABILITATION TODAY}

The Report of the Director General of WHO to the $29 \mathrm{th}$ World Health Assembly in May 1976 included the following:

"Disease-orientated medicine needs to be complemented by disabilityorientated medicine, and it should be realized in every country that the objectives of medicine are not only the prevention and cure of disease, but also the restoration of the individual to normal social function." (WHO, 1976a.)

This statement is of the highest relevance to leprosy workers today, concerned as they are with the most important bacterial cause of crippling disability in the world.

It is now 16 years since the WHO Expert Committee on leprosy defined what rehabilitation in leprosy really meant, in a statement most clear, concise and comprehensive:

"By rehabilitation is meant the physical and mental restoration, as far as possible, of all treated patients to normal activity, so that they may be able to resume their place in the home, society and industry. To achieve this, treatment of the physical disability is obviously necessary, but it must be accompanied by the education of the patient, his family and the public, so that not only can he take his normal place, but society will also be willing to accept him and assist in his complete rehabilitation." (WHO, 1960.)

This Committee was followed by an expert Scientific Meeting on Rehabilitation in Leprosy (WHO, 1961a) which went into the subject in greater detail. The co-ordinated use of medical, social, educational and vocational measures in rehabilitation was also advocated by the WHO Expert Committee on Medical Rehabilitation in 1969 (WHO, 1969).

While notable progress has been made, especially in the curative aspects of rehabilitation in leprosy, the underlying basic principles are still not universally recognized. This is well brought out in the proceedings of a recent 7 Nations Consultation on leprosy in S.E. Asia, organized by WHO at the highest level, and concerned with an area of the world in which there are estimated to be more than 4.5 million sufferers from leprosy. The Consultation honestly admitted that, "the prevention and treatment of deformities were regarded as rather neglected areas in the management of leprosy cases." (WHO, 1967b.)

Some of the reasons for this situation are not far to seek.

1. The average doctor is disease-orientated. If he has met leprosy at all in his medical education, it is likely to have been encountered briefly in the context of bacterial infections or dermatology, with emphasis on chemotherapy, and maybe some reference to remedial surgery. Face to face with the patient, he is likely to be at ease when prescribing dapsone, but feels out of his depth when confronted by the imponderable aspects of the patient's situation, especially if there is no 
physiotherapist or social worker onto whose shoulders responsibility can be shifted. Too often disease-orientated medicine is not complemented by disabilityorientated medicine, and this is a matter of great importance, because without it many of our efforts can become self-defeating. "Thus patients are deprived of aspects of primary patient care which might have saved them from progressive crippling deformity and social, economic, psychological and vocational disability" (10th International Leprosy Congress, 1973).

2. It is simpler to think of rehabilitation in terms of treating visible established deformity than it is to see our primary concern as the prevention of disability. The patient who looks physically normal and is mobile may be a wonderful testimony to the skill of surgeon and physiotherapist, but it should be more satisfying to contemplate those patients who have been saved from the need to consult a surgeon. This means that in rehabilitation we have to go back to root causes. The focal point of our activity is the diagnosis and bringing into care of patients at the earliest possible point in their illness, at a stage when physical disability is minimal and most amenable to treatment. On this basis rehabilitation must be seen as integral to the primary approach to the patient and his community, inseparable from the personal relationship between health worker and the people and the enlightened community attitude which promotes early diagnosis. "Rehabilitation must start on the day of diagnosis" (WHO, 1961b) is a worthy motto for leprosy workers at all levels, but even this is not sufficient. Effective rehabilitation demands that the day of diagnosis is pushed further and further back towards the onset of the first symptoms of leprosy. This will happen only when the stigma has been taken out of leprosy. The objectives of rehabilitation are thus inseparable from community enlightenment and health education.

As long as rehabilitation was thought of in terms of curing disability, its sphere was essentially the institution where the skills of surgeon and physiotherapist were available. These will always be needed, but the trend towards prevention rather than cure places the focal point of rehabilitation activity firmly at the periphery, with major responsibility on the shoulders of the local health worker and medical auxiliary. This is to be welcomed, because it is in line with current thought regarding medicine in developing countries, so clearly expressed in one WHO publication after another. National dignity requires that health planning must realistically relate the primary health needs of the greatest possible number of people to the limited economic resources usually available. In practice this imposes a pattern of medicine in which the front line of primary health care is held by a large corps of community health workers and auxiliaries of whom leprosy workers form a part. The training and orientation of these important members of the leprosy control team are thus extremely important. For them in particular an approach which sees the patient in his wholeness with interest and compassion is the starting point of rehabilitation. This orientation needs to be taught, because it is not the approach to leprosy sufferers which comes naturally to most of us. The Director General of WHO states that radical changes are required in education and training, with a new strong emphasis on the training and utilization of auxiliary and community health workers and their supervisors (WHO, 1976c). Where leprosy is concerned these changes need to relate to the responsible role of the local worker in relation to rehabilitation. We need more manuals in this respect like that of Kapoor (1975), but carrying the subject in even further detail. 
Some interesting facets in rehabilitation are illumined by recent reports from India, where the concept of rehabilitation in leprosy first flowered. In a major report reviewed in this issue, and covering 7 years of research and observation of rehabilitation needs in a large leprosy control programme (Karat et al., 1976), the authors found that out of 6038 patients in the area no less than $40 \%$ suffered from sensory loss or more advanced grades of disability due to leprosy. Bacilliferous types of leprosy were involved more severely than non-bacilliferous types, but regular administration of dapsone in such patients had a beneficial effect on nerve function, and a slow but steady decline in patients needing hospital care for trophic ulcers occurred as the project proceeded. The importance of rehabilitation at primary care level is thus clearly demonstrated. Ranjitkumar and Fritschi (1976) in this issue of Leprosy Review present a preliminary report concentrating on 88 of the most seriously involved patients in the same programme, those already rejected by family and community or in imminent danger of rejection. They have found that by personal assistance and training, domiciliary rehabilitation is in fact possible in a significant number of patients. and at a considerable saving as compared with the cost of sheltered industry. Another slant on the same subject comes from the study by Wright (1976) also in this issue, of 2 communities of rejected patients in India who have actually succeeded in establishing a more satisfactory economic level of living than prevails in the local population, while posing no medical hazard to surrounding villages. These villages illustrate the basic human need for security and affection in a community framework, something which we should never of ficiously try to alter.

The battle for the rehabilitation of leprosy patients has to be fought and won, not in the operating theatre, ulcer ward, physiotherapy department or protected workshop, but at the level of family and village. The rural leprosy worker or community health worker is in the forefront of this battle, and his wise training, supervision and support by those technically more highly qualified are immediate priorities.

T. F. DAVEY

\section{References}

Kapoor, P. (1975). Guide to Leprosy and Leprosy Control. 82 pp. 593/2 Rasta Peth, Poona-411 Oil India: J. M. Mehta.

Karat, S.

comprehensive control programme in the Gudiyattam Taluk, S. India. Printed privately. Ranjitkumar, J. H. and Fritschi, E. (1976). Domiciliary rehabilitation. Lepr. Rev. 47, 295-305.

Tenth International Leprosy Congress, Bergen. (1973). Report of the Committee on Rehabilitation.

WHO (1960). 2nd Report of the Expert Committee on Leprosy. WHO techn. Rep. Ser. 189, 20.

WHO (1961a). Report of Scientific Meeting on Rehabilitation in Leprosy. WHO techn. Rep. Ser. 221.

WHO (1961b). Report of Scientific Meeting on Rehabilitation in Leprosy p. 33, quoting Rehabilitation Literature Aug. 1960 21, No. 8, 243.

WHO (1969). 2nd Report of the Expert Committee on Medical Rehabilitation. WHO techn. Rep. Ser. 419.

WHO (1976a). WHO Chronicle 30, 324.

WHO (1976b). Report on an Inter-Country Consultative Meeting on Leprosy, SEA/Lep./57 p. 9.

WHO (1976c). Press Release WHO/24 of 23/4/1976.

Wright, E. M. (1976). Leprosy villages-are they all outdated? Lepr. Rev. 47, 307-311. 